\title{
Removal of the $\mathrm{N}$-Terminal Residue of a Protein after Transamination
}

\author{
By H. B. F. DIXON AND V. MORET* \\ Department of Biochemistry, University of Cambridge
}

(Received 30 June 1964)

\begin{abstract}
1. Pseudomonas cytochrome c-551 was modified by treatment at $20^{\circ}$ with glyoxylate in the presence of pyridine and cupric sulphate. The change in its chromatographic properties was consistent with conversion of its $\mathrm{N}$-terminal residue into an oxo acyl residue by transamination. 2. The product underwent further modification on treatment with 0 -phenylenediamine or 4-methylphenylene1,2-diamine in strong acetate buffer at $37^{\circ}$. The final product had chromatographic properties and the $N$-terminal residue consistent with its differing from the native cytochrome solely in the absence of the original terminal residue. 3 . The nature of analogous reactions supports these interpretations of the modifications. 4. These two treatments provide a method for specific removal of the $N$-terminal residue of a protein. 5. The intermediate and final products were oxidized by cytochrome oxidase at about the same rate as the original cytochrome.
\end{abstract}

The $N$-terminal residue of a peptide can be converted into an oxo acyl residue by transamination at room temperature (Dixon, 1964a,b). This allows removal of the modified residue by reaction with a substance that contains two nucleophilic groups, one of which combines with the carbonyl group and so places the other favourably for a displacement reaction to break the peptide bond (Dixon, 1964a). We decided to investigate whether these reactions could be applied to a protein and whether the terminal residue could be removed without other change of structure. Since the positive charge of the terminal amino group should be destroyed by the first reaction, and a positive charge on a new terminal group be formed in the second, it was convenient to choose a protein that could be separated simply from molecules from which it differed in charge. Chromatographic methods involving ion exchange were available for cytochromes of the $c$ type. Since, however, mammalian cytochromes $c$ do not possess a free terminal amino group, cytochrome c-551 from Pseudomonas fluorescens was used for this work. Since this has a terminal glutamyl residue (Ambler, 1963a,b), the conversions looked for and found to occur were from (I) into (II) and from (II) into (III).<smiles>[NH3+]C(CC(=O)[O-])C(=O)[O-]</smiles>

(I)

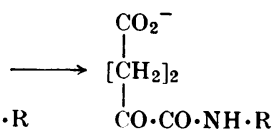

(II)
$\stackrel{+}{\mathrm{NH}_{3}} \cdot \mathrm{R}$
* Present address: Istituto di Chimica Biologica, Università, Padova, Italy.

\section{EXPERIMENTAL}

\section{Materials}

Pseudomonas cytochrome c-551 prepared by the method of Ambler (1963a) was given to us by Dr R. P. Ambler in a solution of $0.05 \mathrm{~N}$-acetic acid adjusted to $\mathrm{pH} 3.9$ with ammonia. CM-cellulose was prepared by the method of Peterson \& Sober (1961) from unsieved Whatman cellulose powder, except that the product was not dried. Lumps were broken in dilute suspension by using a homogenizer manually.

Acetone selenosemicarbazone was made from acetone, hydrazine hydrate and potassium selenocyanate by the method of Huls \& Renson (1956a). Ammonium dithiocarbazate $\left(\mathrm{NH}_{2} \cdot \mathrm{NH} \cdot \mathrm{CS}_{2}-\mathrm{NH}_{4}{ }^{+}\right)$was made from hydrazine hydrate, carbon disulphide and ammonia by the method of Losanitch (1921). 3,4-Diaminoanisole dihydrochloride was made by reduction of 3-amino-4-nitroanisole with stannous chloride in conc. $\mathrm{HCl}$, precipitation of tin with $\mathrm{H}_{2} \mathrm{~S}$ after dilution, and evaporation of the filtrate. The product was recrystallized from methanol on the addition of ether. 4-Phenyl-3-thiosemicarbazide was made from phenyl isothiocyanate and hydrazine hydrate by the method of Pulvermacher (1894). Pyruvamide was made by hydrolysis of pyruvonitrile prepared from acetyl bromide and cuprous cyanide, approximately according to the method of Anker (1948), but only a small yield was obtained. Pyruvoylglycine was made from pyruvic acid and glycine by using toluene- $p$-sulphonyl chloride by the method of Dixon $(1964 b)$. Other materials were obtained commercially, and of these 0 -phenylenediamine and 4-methylphenylene-1,2diamine were recrystallized, from water and light petroleum respectively, before use.

Cytochrome oxidase was prepared from Pseudomonas fluorescens (kindly supplied by Dr R. P. Ambler) by the method of Yamanaika \& Okunuki (1963) and was purified up to the stage at which they added $\left(\mathrm{NH}_{4}\right)_{2} \mathrm{SO}_{4}$ to 
crystallize the enzyme. Yeast cytochrome $c$ was extracted from brewer's yeast by the method of Armstrong, Coates \& Morton (1961) in $1 \mathrm{M}-\mathrm{NaCl}$, and adsorbed on to the carboxylic resin Amberlite IRC-50 equilibrated with 0.07 $\mathrm{M}-\mathrm{NaH}_{2} \mathrm{PO}_{4}-$ $0 \cdot 14 \mathrm{M}-\mathrm{Na}_{2} \mathrm{HPO}_{4}$ solution after fourfold dilution of the extract. It was displaced from the resin with $0.07 \mathrm{M}$ $\mathrm{NaH}_{2} \mathrm{PO}_{4}-0 \cdot 14 \mathrm{M}-\mathrm{Na}_{2} \mathrm{HPO}_{4}-\mathrm{l} \mathrm{M}-\mathrm{NaCl}$ solution.

\section{Methods}

Release of glycine from pyruvoylglycine. After incubation of pyruvoylglycine solution (usually $0.8 \mathrm{~mm}$ ) under various conditions, a sample (about $50 \mu \mathrm{l}$.) was put on paper for electrophoresis at pH 2 by the method of Michl (1951). The glycine on the paper was measured by reaction with ninhydrin in the presence of cadmium acetate according to the method of Heilmann, Barrollier \& Watzke (1957).

Chromatography and gel filtration. Columns (1 cm. diam. $\times$ approx. $40 \mathrm{~cm}$. long) were packed with CM-cellulose and equilibrated with buffer. Samples of the cytochrome or its derivatives were applied in the chromatographic buffer, and were introduced into this from any other reaction medium by gel filtration. This was performed on a cross-linked dextran (Sephadex G-25, medium grade) in columns of $1 \mathrm{~cm}$. diam. Since the cytochrome was partly reduced during some of the treatments used, it was reoxidized by applying $1 \mathrm{ml}$. of $1 \mathrm{~mm}$-potassium ferricyanide followed by $0.3-0.5 \mathrm{ml}$. of the buffer to the column of dextran just before the cytochrome sample. The cytochrome thus passed through the zone of ferricyanide after separation from other reagents, and was separated in turn from the ferri- and ferro-cyanides. Columns about $30 \mathrm{~cm}$. long were used, samples (up to $2 \mathrm{ml}$.) were applied, and the coloured cytochrome band was collected in about $4 \mathrm{ml}$. and applied to the CM-cellulose column.

20 mM-Sodium acetate- $30 \mathrm{mN}$-acetic acid solution was suitable for chromatographing the cytochrome (Fig. l $a$ ) and derivatives with fewer positive charges, such as the product of transamination and the reduced form (Fig. 1b). The derivative (III), shown to lack the terminal glutamyl residue, and which therefore possessed a smaller negative charge, moved inconveniently slowly in this buffer, so that $25 \mathrm{~mm}$-sodium acetate- $30 \mathrm{mN}$-acetic acid solution was used. All buffers for chromatography contained $0.03 \%$ of toluene. A flow rate of about $1 \mathrm{ml} . / \mathrm{min}$. was used with columns of dimensions $1 \mathrm{~cm} . \times$ approx. $40 \mathrm{~cm}$., and the total running time was under $4 \mathrm{hr}$. The columns exhibited 2.5 plates $/ \mathrm{cm}$. under these conditions, calculated by the method of Stack-Dunne (cited by Dixon, 1962).

Transamination of cytochrome. To $23 \mathrm{mg}$. of glyoxylic acid hydrate were added $50 \mu \mathrm{l}$. of $0 \cdot 1 \mathrm{M}-\mathrm{CuSO}_{4}$ and $50 \mu \mathrm{l}$. of pyridine (cf. Mix \& Wilcke, 1960; Mix, 1961 $a, b$ ). Then $0.4 \mathrm{ml}$. of cytochrome solution was added. The buffering of the ammonium acetate in the cytochrome solution was negligible compared with that of the pyridine and glyoxylic acid, and this concentration of pyridine $(1.25 \mathrm{M})$ and glyoxylic acid $(0.5 \mathrm{M})$ gave $\mathrm{pH} 5.6$. After $15 \mathrm{~min}$. the reaction was stopped by removing the cytochrome from the medium by gel filtration. When the product was to be chromatographed it had to be oxidized by the method described above. When, however, it was to be treated directly with a further reagent, the gel filtration was performed on a small column $(1 \mathrm{~cm} . \times 10 \mathrm{~cm}$.) and the cytochrome transferred into the reaction medium.
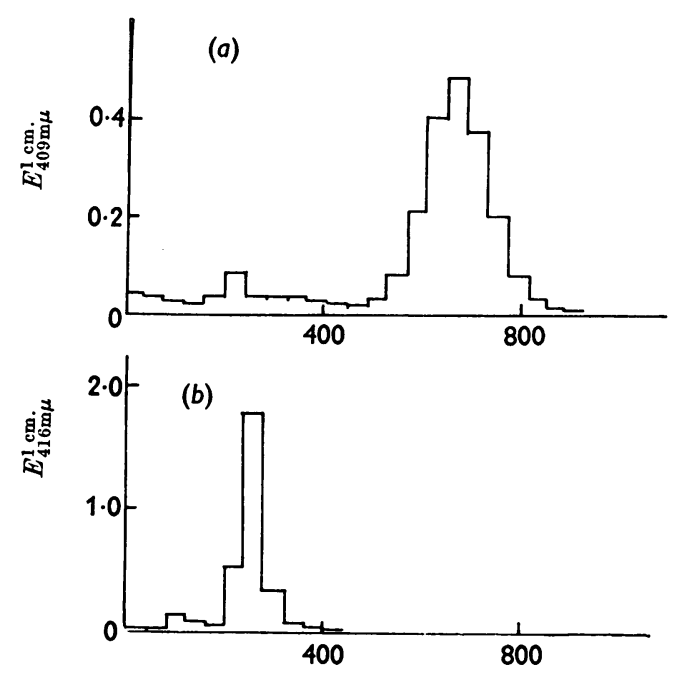

Vol. of effluent (ml./100 ml. column vol.)

Fig. 1. Chromatograms of cytochrome. A column $\mathbf{( 0 \cdot 8 7}$ $\mathrm{cm} .{ }^{2} \times 41 \mathrm{~cm}$.) of CM-cellulose was equilibrated and developed with $20 \mathrm{~mm}$-sodium acetate-30 $\mathrm{mN}$-acetic acid containing toluene $(0 \cdot 03 \%)$. (a) Oxidized cytochrome: $80 \%$ of the applied material was recovered as judged by extinction at $409 \mathrm{~m} \mu$. (b) Reduced cytochrome: $1.5 \mathrm{mg}$. of ascorbic acid was added to the sample, and the buffer contained $1 \mathrm{~mm}$-ascorbic acid and $0 \cdot 1 \mathrm{~mm}$-EDTA as additional components.

Scission reaction. Since many of the reagents used were oxidized slowly by air, the incubation excluded air as follows. Treatment with 4-methylphenylene-1,2-diamine is described, since it was found to be the most satisfactory. The cytochrome was transferred to $2 \mathrm{M}$-sodium acetate$2 \mathrm{~N}$-acetic acid solution by the gel filtration, and collected in a test tube that had been narrowed in the middle. The volume was determined from the weight of the sample collected and the density of the buffer, and enough diamine was added to make a $20 \mathrm{~mm}$ solution. The tube was evacuated with a water pump, and the degassed solution was sealed by heating the constriction of the tube. The tube was incubated at $37^{\circ}$ overnight. The cytochrome from the sample was transferred into the chromatographic buffer by gel filtration. Oxidation products of the diamine were adsorbed to the dextran and were removed by washing the column with $60 \%(v / v)$ acetic acid before re-equilibration with buffer.

Concentration of cytochromes. Each of the cytochrome derivatives was concentrated from the effluent of chromatograms by mixing with an equal volume of $1 \mathrm{~N}$-acetic acid and running through a column $(2 \mathrm{~cm}$. diam. $\times 4 \mathrm{~cm}$.) of CM-cellulose equilibrated with the same mixture of chromatographic buffer and acetic acid. The adsorbed cytochrome was displaced with $0 \cdot 1 \mathrm{M}$-sodium acetate-0.1 N-acetic acid.

Identification of $\mathrm{N}$-terminal residue. The cytochrome was transferred into buffer (8 M-urea dissolved in $0.2 \mathrm{M}-N$ ethylmorpholine solution adjusted to $\mathrm{pH} 8.5$ with acetic acid) by gel filtration. To $3 \mathrm{ml}$. of this solution $0.08 \mathrm{ml}$. 
of 1-fluoro-2,4-dinitrobenzene was added and the mixture was stirred at $37^{\circ}$ for $3 \mathrm{hr}$. Thereafter the second procedure of Ambler (1963a) was followed. The DNP-amino acid released by hydrolysis was identified by thin-layer chromatography by using the benzyl alcohol-chloroform-acetic acid system of Brenner, Niederwieser \& Pataki (1961).

Determination of oxidation by cytochrome oxidase. The cytochrome solution under study was reduced with excess of ascorbic acid and transferred into a solution of 0.04-M$\mathrm{NH}_{4} \mathrm{H}_{2} \mathrm{PO}_{4}$ (adjusted to $\mathrm{pH} \mathrm{6.5}$ with $0.04 \mathrm{~N}-\mathrm{NH}_{3}$ solution) by gel filtration. Its oxidation was studied by following the decrease of extinction at $551 \mathrm{~m} \mu$ after adding Pseudomonas cytochrome oxidase $(0.1 \mathrm{ml}$.) to $3.5 \mathrm{ml}$. of cytochrome. Cytochrome solutions under comparison were diluted to have the same initial extinction of about 0.5 for a $1 \mathrm{~cm}$. light-path.

\section{RESULTS}

Preliminary experiments. Since $\alpha$-oxo acids are easily oxidized to carbon dioxide and a new acid:

$$
\mathrm{R} \cdot \mathrm{CO} \cdot \mathrm{CO}_{2} \mathrm{H}+\mathrm{O} \rightarrow \mathrm{R} \cdot \mathrm{CO}_{2} \mathrm{H}+\mathrm{CO}_{2}
$$

the action of several oxidizing agents on pyruvamide was studied in the hope of finding a method of splitting an oxo acid residue off a peptide chain. The unchanged oxidizing agent was determined at intervals. Ceric sulphate, hydrogen peroxide, sodium bismuthate and sodium periodate were used since all oxidize $\alpha$-oxo acids. In each case the rate of reaction with pyruvamide was only a minute fraction of that with pyruvic acid. This is not surprising since such an oxidation of an oxo acyl peptide would involve elimination of a protonated isocyanate $\mathrm{O}=\mathrm{C}=\stackrel{+}{=} \mathrm{N} \cdot \mathrm{R}$ rather than of carbon dioxide. McGregor \& Carpenter (1962) achieved oxidation of oxo acyl peptides with hydrogen peroxide, but used $0 \cdot 1 \mathrm{~N}$-potassium hydroxide at $37^{\circ}$ as the medium.

Dr D. M. Brown and Dr V. M. Clark called our attention to reagents for $\alpha$-oxo acids that have two nucleophilic groups, e.g. thiosemicarbazide (Bougault \& Daniel, 1928) and o-phenylenediamine (Hinsberg, 1887). Pyruvoylglycine was easier to prepare than pyruvamide, and the scission of its peptide bond was easier to detect since glycine was released. As Dixon (1964a) reported, glycine was formed on incubation of the thiosemicarbazone of pyruvoylglycine at $57^{\circ}$ and $\mathrm{pH} 10$.

A number of treatments were tested to try to find milder conditions for such release. The formation of the thiosemicarbazone was first studied, and found to be complete with $0.8 \mathrm{~mm}$-pyruvoylglycine in 5 min. at room temperature in formate buffer (40 mM-thiosemicarbazide in $0.2 \mathrm{~N}$-formic acid), as judged by increase of extinction at $340 \mathrm{~m} \mu$. It was slower in acetate buffer ( $40 \mathrm{~mm}$-thiosemicarbazide in $0.2 \mathrm{M}$-sodium acetate- $0.2 \mathrm{~N}$-acetic acid), and slower still if little acetic acid was present $(40 \mathrm{~mm}$ thiosemicarbazide in $16 \mathrm{mN}$-acetic acid). After
$5 \mathrm{~min}$. in $0.2 \mathrm{~N}$-formic acid at room temperature, with an excess of either thiosemicarbazide or acetone selenosemicarbazone, an equal volume of $0.8 \mathrm{M}$-sodium metaborate was added and the mixture incubated for $27 \mathrm{hr}$. at $27^{\circ}$. The yield of glycine was $30-40 \%$. The yield was much less when $0.4 \mathrm{M}$-sodium metaborate was added, i.e. a ratio of borate to boric acid $1: 1(\mathrm{pH} \mathrm{9.4)}$ rather than 2:1 (pH 9.7). The formation of the selenosemicarbazone of the pyruvoylglycine from the derivative of acetone is the method found to work by Huls \& Renson (1956b) for aldehydes but not for ketones; evidently the presence of the peptide bond beside the ketone group in pyruvoylglycine makes it more reactive than most ketones.

Since we thought that the reaction proceeded faster as the $\mathrm{pH}$ was raised because of the conversion<smiles>[R]NC(=O)NN=C([R])N[R]</smiles>

(IV)

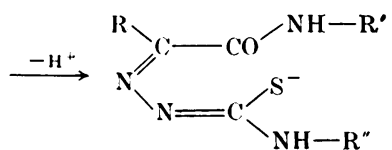

(V) of (IV) into (V) so as to produce a nucleophilic group well placed to attack the peptide bond, we decided to make the group $\mathrm{R}^{\prime \prime}$ electron-attracting to facilitate loss of a proton, in the hope that the reaction would proceed at a lower $\mathrm{pH}$. 4-Phenyl-3thiosemicarbazide was therefore tried. Traces of glycine were indeed released at $\mathrm{pH} 7$, which were not found with thiosemicarbazide, but the amount fell off as the $\mathrm{pH}$ was raised. The slowness of reaction may be because the electron-attracting phenyl group not only facilitates the ionization, but also makes the ionized form a less powerful nucleophile.

Some glycine was released on incubation with ammonium dithiocarbazate. The $\mathrm{pH}$ was hard to control since the reagent decomposed to raise the $\mathrm{pH}$ of more acid buffers to about 8 .

$o$-Phenylenediamine $(17 \mathrm{~mm})$ released $60-70 \%$ of the glycine from $8 \mathrm{~mm}$-pyruvoylglycine in $17 \mathrm{mN}$-acetic acid on incubation for $22 \mathrm{hr}$. at $37^{\circ}$, and similar yields in other acetate buffers of lower and higher $\mathrm{pH}$ values. This reagent therefore appeared suitable for reaction with transaminated proteins.

Transamination of cytochrome. The cytochrome was treated for $15 \mathrm{~min}$. in $10 \%(\mathrm{v} / \mathrm{v})$ pyridine with $0.5 \mathrm{~m}$-glyoxylic acid and $10 \mathrm{~mm}$-cupric sulphate. It was then transferred into $20 \mathrm{~mm}$-sodium acetate$30 \mathrm{mN}$-acetic acid buffer through $1 \mathrm{~mm}$-ferricyanide by gel filtration. The sample was chromatographed on CM-cellulose. Fig. 2(a) shows the result. No material with the $R_{F}$ of the original cytochrome remained, but a faster peak was present. That the 


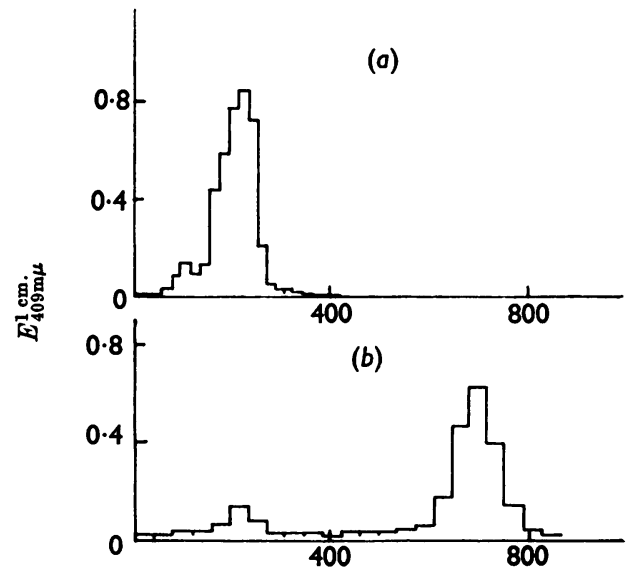

Vol. of effluent (ml./100ml. column vol.)

Fig. 2. Chromatograms of transaminated cytochrome and control. The conditions were as given in Fig. 1. (a) Transaminated cytochrome. (b) Cytochrome treated as in (a) except for the omission of cupric sulphate and longer treatment.

peak is less held by CM-cellulose is consistent with the loss of a positive charge on production of (II) from (I). As a control, Fig. 2(b) shows the result of treating the cytochrome for $30 \mathrm{~min}$. with the pyridine and glyoxylic acid but with the cupric sulphate omitted. Most of the material was unchanged.

Attempts to confirm the nature of the reaction by reversing the transamination were unsuccessful. These were made in $10 \%$ pyridine with $0 \cdot 1 \mathrm{M}$-cupric sulphate, $0.4 \mathrm{~N}$-acetic acid and either $0.1 \mathrm{M}$-alanine (for $20 \mathrm{~min}$.) or glycine (for $30 \mathrm{~min}$.). Possibly ketones react to form the intermediate Schiff base much more slowly.

Removal of the oxo acyl residue. It was not necessary to chromatograph the product of transamination before submitting it to a treatment that was to be tested for ability to remove the oxo acyl residue. This was partly because the desired product (III) differed in charge, not only from the transaminated material (II), but also from the native cytochrome (I), since the residue to be removed was acidic. It could therefore be expected to separate from them on chromatography. Further, the transamination appeared to be quantitative, so that no native cytochrome should remain after treatment with glyoxylate. The appearance of a peak more retarded by CM-cellulose than the native cytochrome was taken as an indication that the desired reaction might have been achieved.

The transaminated protein was put into the medium under test by gel filtration, reagents were added and, if any reagent was liable to aerobic oxidation, the tube containing the mixture was sealed under reduced pressure. The tube was maintained at $37^{\circ}$ overnight. After incubation the product was introduced into the chromatographic buffer through $1 \mathrm{~mm}$-ferricyanide by gel filtration, and chromatographed on CM-cellulose.

No more retarded product was found on incubation with $0.1 \mathrm{M}$-ammonium dithiocarbazate in phosphate buffer. This failure with a protein after some success with pyruvoylglycine is reminiscent of the breakdown of the stepwise method of Léonis \& Levy (1954) when applied to peptides of considerable length. In that method too a $-\mathrm{CS}_{2}-$ group was involved, but since very little work was done with the dithiocarbazate it is not certain that the cause is the same.

Thiosemicarbazide $(25 \mathrm{~mm})$ in a carbonatebicarbonate buffer gave only a very small yield of a more retarded peak.

$o$-Phenylenediamine gave considerable amounts of a more retarded peak when incubated in acetate and formate buffers. The yield was, however, variable until we realised that the reaction might be subject to general acid catalysis, and that its rate therefore depended on the concentration of acetic acid or formic acid in the medium rather than on the $\mathrm{pH}$. Thus the area of the retarded peak as a percentage of the total material recovered from the chromatogram after incubation for $21 \mathrm{hr}$. at $37^{\circ}$ with $20 \mathrm{~mm}$-phenylenediamine in $0.1 \mathrm{~N}$-acetic acid was $25 \%$, but was $52 \%$ with 20 mM-phenylenediamine in $0.5 \mathrm{M}$-sodium acetate-2 $\mathrm{N}$-acetic acid. From the $\mathrm{p} K$ values of phenylenediamine and acetic acid, the $\mathrm{pH}$ of the latter solution may be presumed to be slightly the higher. The yield was similarly $55 \%$ in $14.2 \mathrm{hr}$. in $1.25 \mathrm{~m}$-sodium acetate$5 \mathrm{~N}$-acetic acid, but in this medium the cytochrome changed colour and regained its previous colour on dilution. The yield was $55 \%$ in $14.6 \mathrm{hr}$. in $2 \mathrm{M}$ sodium acetate-2 $\mathrm{N}$-acetic acid (Fig. 3). The yield

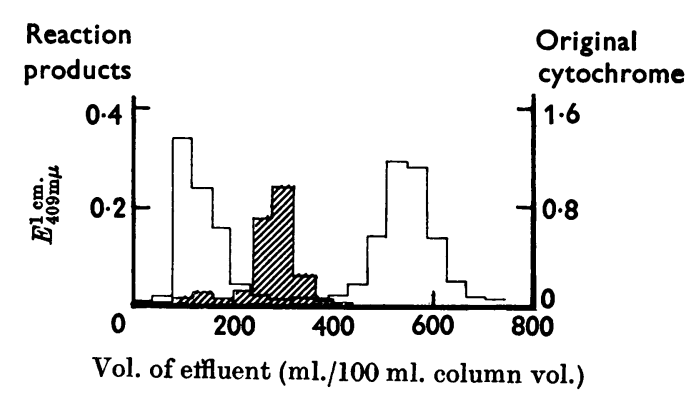

Fig. 3. Chromatograms of products of phenylenediamine treatment of transaminated cytochrome and ( ${ }^{0}$ ) original cytochrome. The conditions were as given in Fig. 1 except that the sodium acetate concentration was $25 \mathrm{~mm}$. 
was not greatly affected by changing the concentration of phenylenediamine within the limits of 10 to $50 \mathrm{~mm}$. This yield of $55 \%$ of the material recovered from the chromatogram was $39 \%$ of the cytochrome originally used for transamination.

Since the independence of the rate from the concentration of diamine suggested that the formation of the Schiff base (VI) was virtually complete,<smiles>[R]NCC([R])=Nc1ccccc1N</smiles>

(VI)

the limiting step was probably the subsequent reaction. It could therefore be accelerated by increasing the availability of electrons on the amino

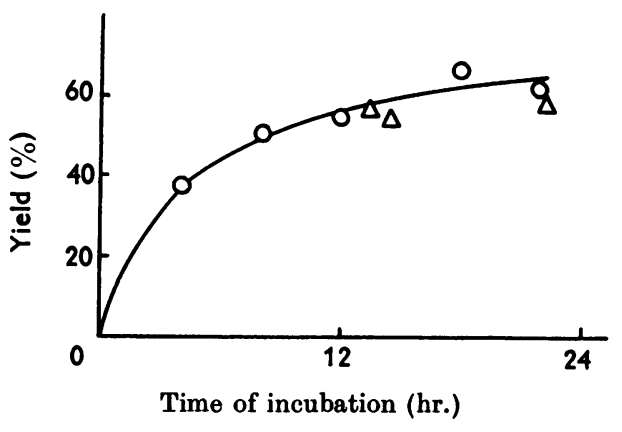

Fig. 4. Yields of slower peak after different times of treatment with $20 \mathrm{~mm}$-diamine at $37^{\circ}$ in 2 M-sodium acetate$2 \mathrm{~N}$-acetic acid. The yield is expressed as a percentage of the total material recovered from the column. O, 4-Methylphenylene-1,2-diamine; $\Delta, o$-phenylenediamine.
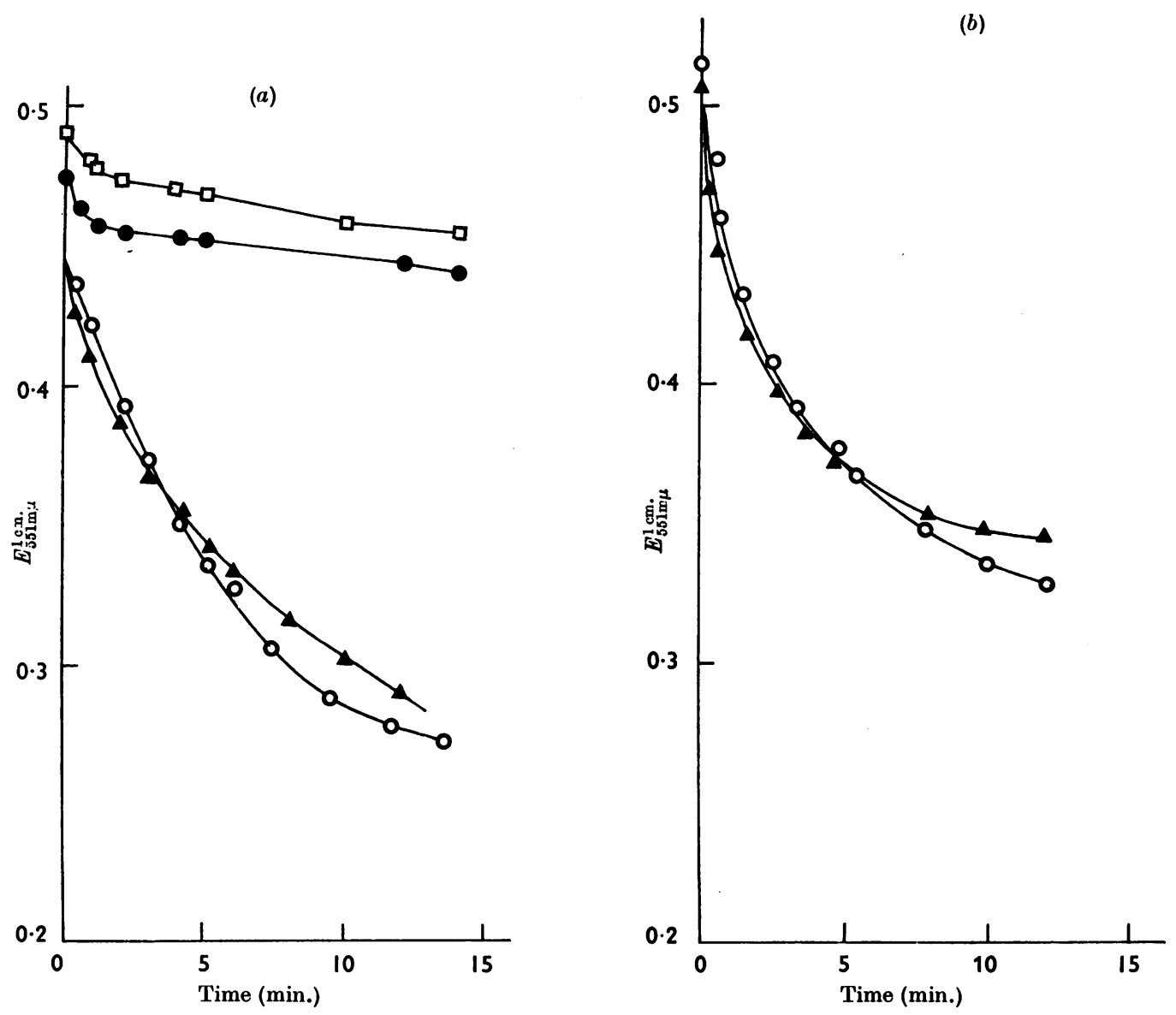

Fig. 5. Course of oxidation of cytochrome derivatives with Pseudomonas cytochrome oxidase. (a) $O$, Modified cytochrome (III); $\Delta$, native cytochrome (I); $\square$, yeast cytochrome $c$; $\bullet$, horse cytochrome $c$. (b) $\Delta$, Transaminated cytochrome (II); O, modified cytochrome (III). 
group. A reagent with an additional methyl group, 4-methylphenylene-1,2-diamine, was therefore tried, also at $20 \mathrm{~mm}$ concentration. Fig. 4 shows the results with various times of treatment with this amine and with phenylenediamine. There is no great difference in total yield. Similarly 3,4diaminoanisole did not give an improvement. In case this failure was because the one amino group made more reactive in these compounds was bound in the Schiff base, 4,5-dimethylphenylene-1,2diamine was tried, but without improvement. No product at all was formed with 2,3-diaminopyridine, 4,5-diaminopyrimidine or 5,6-diamino-2,4-dihydroxypyrimidine. Some of these were added as salts, since at $20 \mathrm{~mm}$ concentration they did not greatly alter the composition of the strong acetate buffer. In case a nitrogen atom could act similarly when bound in a ring, transaminated cytochrome was similarly incubated for $8-14 \mathrm{hr}$. at $37^{\circ}$ in $2 \mathrm{M}$ sodium acetate- $2 \mathrm{~N}$-acetic acid with a $0.1 \mathrm{M}$ concentration of each of the following: 2-aminopyridine, 2-aminopyrimidine, 2-aminothiazole and (in a buffer of one-twentieth the concentration) 2-amino-4-hydroxypyrimidine (cytosine). In none of these cases was a retarded peak formed.

$\mathrm{N}$-Terminal residue. Material from the more retarded peak obtained after treatment of the cytochrome with glyoxylate and aromatic diamine was analysed for $N$-terminal residue by treatment with 1-fluoro-2,4-dinitrobenzene. The DNP-amino acid extracted with ether from the hydrolysate of the DNP-protein ran with DNP-aspartic acid on thin-layer chromatography and was separated from DNP-glutamic acid. Since aspartic acid is the penultimate residue of the cytochrome (Ambler, $1963 b$ ), this confirms the hypothesis that the protein had been modified by removal of its terminal residue.

Oxidation by cytochrome oxidase. Fig. $5(a)$ shows the course of oxidation by cytochrome oxidase from Pseudomonas of the native cytochrome and its derivative made by removal of the terminal residue. Both are oxidized at about the same rate. Fig. 5(a) also shows that cytochromes $c$ from horse and yeast are oxidized much less rapidly (if at all) by this preparation. The transaminated cytochrome is also oxidized at about the same rate as the cytochrome modified by removal of the residue (Fig. $5 b$ ).

Transamination of lysozyme. A sample (40 mg.) of lysozyme from egg was incubated at room temperature for $1 \mathrm{hr}$. in a solution of $10 \%$ pyridine, $50 \mathrm{~mm}$-cupric sulphate and $0.5 \mathrm{M}$-glyoxylic acid, and desalted by adsorbing it on to a carboxylic resin, washing the salts out with $5 \%$ acetic acid and displacing the product with $60 \%$ acetic acid (Dixon, 1959). On chromatography in the system of Tallan \& Stein (1953) a considerable part appeared unchanged. Lysozyme is therefore transaminated much more slowly than cytochrome, whether because of lower accessibility of its terminal residue or because this residue (lysine) differs from that of the cytochrome. The modified material appeared heterogeneous on chromatography.

\section{DISCUSSION}

The direct evidence that the change on glyoxylate treatment is the transamination represented as $(\mathrm{I}) \rightarrow(\mathrm{II})$ is limited to the change in chromatographic properties and the subsequent change on treatment of the product with a diamine. There is also the evidence by the analogy that the conditions used are those known to give transamination of amino acids, and also of the $N$-terminal residues of peptides (Cennamo, Carafoli \& Bonetti, 1956; Dixon, 1964a,b).

There are similarly two lines of evidence that the diamine treatment brought about scission of the oxo acyl residue, i.e. (II) $\rightarrow$ (III). In addition to the characterization of the product, there is the analogy of the reaction of aromatic diamines with other compounds. They are well known to react with $\alpha$-oxo acids, and they liberate glycine from pyruvoylglycine as shown in the preliminary experiments.

The characterization of the product consisted of showing the expected $N$-terminal residue and the expected change in chromatographic position. No direct checks were made to ensure that all other residues in the molecule were intact and unmasked. The unchanged rate of reaction of the cytochrome with cytochrome oxidase does, however, provide some evidence that no substantial change in structure, whether covalent or conformational, had occurred. This reaction proved specific in that mammalian and yeast cytochromes did not react with the Pseudomonas cytochrome oxidase, but unspecific in the sense that it was unaffected by the absence of any terminal amino group, since the transaminated intermediate product reacted equally well. It is not possible to state how large a change in structure could have taken place without being detected by a change in the rate of enzymic oxidation.

The results therefore show that it is possible to remove the $N$-terminal residue from a protein as described. Hence it is interesting to know the advantages and limitations of the method. Excellent procedures already exist for the stepwise removal of residues with the aim of identifying them. The present method is preferable only in the sense that proteins may conceivably be submitted to its milder conditions without their being denatured, and since no general reagent for all amino groups is used proteins should suffer no change in covalent structure other than the loss of the ter- 
minal residue. The method might therefore be useful in studies on the role of the different residues of a protein in its biological activity.

The range of application of the method has not been studied. The experience with lysozyme shows that conditions suitable for the cytochrome may fail to work with other proteins. A terminal residue might be masked inside the protein molecule, and although groups charged at neutral $\mathrm{pH}$ are usually available to titration (Tanford, 1958), Guidotti \& Konigsberg (1964) have shown specific masking of the amino groups of the $\beta$-chains of haemoglobin. Residues of different amino acids, as well as the same residue in different environments, may react at very different rates both in the desired reaction and in side reactions. Some proteins may be precipitated by the copper salt in the presence of pyridine, and, although heavy positive ions are particularly effective precipitants at mildly alkaline $\mathrm{pH}$, haemoglobin was found to be precipitated under the conditions used for transaminating the cytochrome, i.e. at $\mathrm{pH} \mathbf{5 \cdot 6}$. For these reasons it is hard to predict how widely the method can be applied.

The general acid catalysis shown in the scission reaction is unlikely to be due to any step in the formation of the Schiff base (VI), since the yield was not greatly increased on raising the concentration of the diamine. It is probably due either to the increased reactivity of the peptide carbonyl group in the presence of acids, so that the carbon atom is more positive and reacts faster with the aromatic amino group, or to the need to protonate the $\mathrm{NH}^{-}$ group as it is being eliminated to form the terminal amino group of the modified protein.

It is strange that the scission reaction shows characteristics so different from that studied by Holley \& Holley (1952), and in particular that it is so much slower. It may be possible to find another reagent with two nucleophilic groups that will react faster, and so improve the yield. An aromatic amino group is effective presumably because, although it is a powerful nucleophile, it is not protonated too extensively at the $\mathrm{pH}$ of the reaction, and because a nascent aromatic ring stabilizes the transition complex.

We thank Professor F. G. Young for encouragement, Miss M. B. Thomas and Mrs S. K. Earl for their skilled assistance, Dr R. P. Ambler for gifts of the cytochrome, and him and many other colleagues, including especially Dr V. M. Clark, Dr D. M. Brown, Dr N. K. Hamer, Dr E. F. Hartree and Mr M. Wallis, for helpful discussion and advice. We are also grateful to the Consiglio Nazionale delle Ricerche of Italy for the award of a N.A.T.O. Science Fellowship to V.M. and to the Medical Research Council for a grant.

\section{REFERENCES}

Ambler, R. P. (1963a). Biochem.J. 89, 341.

Ambler, R. P. (1963b). Biochem.J. 89, 349.

Anker, H. S. (1948). J. biol. Chem. 176, 1333.

Armstrong, J. McD., Coates, J. H. \& Morton, R. K. (1961). In Haematin Enzymes, p. 385. Ed. by Falk, J. E., Lemberg, R. \& Morton, R. K. Oxford: Pergamon Press Ltd.

Bougault, J. \& Daniel, L. (1928). C.R. Acad. Sci., Paris, 186, 1216.

Brenner, M., Niederwieser, A. \& Pataki, G. (1961). Experientia, 17, 145.

Cennamo, C., Carafoli, B. \& Bonetti, E. D. (1956). J. Amer. chem. Soc. 78, 3523.

Dixon, H. B. F. (1959). Biochim. biophys. Acta, 34, 251.

Dixon, H. B. F. (1962). J. Chromat. 7, 467.

Dixon, H. B. F. (1964a). Biochem.J. 90, 2c.

Dixon, H. B. F. (1964b). Biochem. J. 92, 661.

Guidotti, G. \& Konigsberg, W. (1964). J. biol. Chem. 239, 1474.

Heilmann, J., Barrollier, J. \& Watzke, E. (1957). HoppeSeyl.Z. 309, 219.

Hinsberg, O. (1887). Liebigs Ann. 237, 327.

Holley, R. W. \& Holley, A. D. (1952). J. Amer. chem. Soc. $\mathbf{7 4}, 5445$.

Huls, R. \& Renson, M. (1956a). Bull. Soc. chim. Belg. 65, 511 .

Huls, R. \& Renson, M. (1956b). Bull. Soc. chim. Belg. 65, 684.

Léonis, J. \& Levy, A. L. (1954). C.R. Lab. Carlsberg, Sér. chim., 29, 87.

Losanitch, S. M. (1921). J. chem. Soc. 119, 763.

McGregor, W. H. \& Carpenter, F. H. (1962). Biochemistry, $1,53$.

Michl, H. (1951). Mh. Chem. 82, 489.

Mix, H. (1961a). Hoppe-Seyl. Z. 323, 173.

Mix, H. (1961b). Hoppe-Seyl.Z. 325, 106.

Mix, H. \& Wilcke, F. (1960). Hoppe-Seyl. Z. 318, 148.

Peterson, E. A. \& Sober, H. A. (1961). Biochem.Prep. 8, 45.

Pulvermacher, G. (1894). Ber. dtsch. chem. Ges. 27, 613.

Tallan, H. H. \& Stein, W. H. (1953). J. biol. Chem. 200, 507.

Tanford, C. (1958). In Symposium on Protein Structure, p. 35. Ed. by Neuberger, A. London: Methuen and Co. Ltd.

Yamanaika, T. \& Okunuki, K. (1963). Biochim. biophys. Acta, 67, 379. 